
\title{
25 Research Square \\ Graded Reconstruction Strategy Using a Multi-Layer Technique without Lumbar Drainage After Endoscopic Endonasal Surgery
}

\section{Chang-Min $\mathrm{Ha}$}

Samsung Medical Center

\section{Sang Duk Hong}

Samsung Medical Center

Jung Won Choi

Samsung Medical Center

Ho Jun Seol

Samsung Medical Center

Do-Hyun Nam

Samsung Medical Center

Jung-Il Lee

Samsung Medical Center

Doo-Sik Kong ( $\nabla$ neurokong@gmail.com )

Samsung Medical Center https://orcid.org/0000-0002-7519-3594

\section{Research Article}

Keywords: endoscopic endonasal surgery (EES), cerebrospinal fluid (CSF), novel material, injectable hydroxyapatite (HXA),

Posted Date: July 28th, 2021

DOl: https://doi.org/10.21203/rs.3.rs-749900/v1

License: (c) (1) This work is licensed under a Creative Commons Attribution 4.0 International License. Read Full License 


\section{Abstract}

\section{Introduction}

Sellar reconstruction following endoscopic endonasal surgery (EES) requires modification based on the degree of cerebrospinal fluid (CSF) leak. For high-flow (grade II or III) intraoperative CSF leak, lumbar drainage (LD), in addition to the multi-layer closing technique, is generally recommended. However, LD has complications occasionally, including post-puncture headache, over-drainage symptoms, and increased length of stay (LOS). We retrospectively evaluated the outcome of our graded reconstruction strategy using a multi-layer technique with a novel material, without LD, after EES.

\section{Methods}

Ninety-seven patients who underwent EES with grade II or III intraoperative CSF leak between June 2020 and March 2021 were retrospectively reviewed. For grade II CSF leak, fibrin sealant and a nasoseptal flap (NSF) were placed; for grade III CSF leak, a multi-layer technique was utilized in combination with collagen matrix, an acellular dermal graft, injectable hydroxyapatite (HXA), and an NSF. Postoperatively, routine LD was not performed.

\section{Results}

This study included 48 (49.5\%) grade II and 49 (50.5\%) grade III CSF leaks. Upon follow-up period (mean, 8.7 months), no patient showed postoperative CSF leak in either group. The postoperative LOS was not significantly different between the grade II (6.68 [range, 3-14] days) and grade III CSF leak groups (7.38 [range, 4-15] days) ( $p>0.05)$. No HXA-associated complications occurred.

\section{Conclusions}

A graded surgical repair strategy after EES could avoid postoperative CSF leak. Combined use of injectable HXA and acellular dermal grafts for high-flow CSF leak can limit LD requirement, without significant risks.

\section{Introduction}

Recent advances in endoscopic neurosurgical techniques have made the endoscopic endonasal surgery (EES) a primary surgical option for the treatment of skull base lesions [1-5]. Despite its widespread application in a variety of skull base lesions and several clinical advantages, complications related to EES should not be overlooked [6, 7]. Among them, postoperative cerebrospinal fluid (CSF) leak is the most common and fatal complication to occur after the introduction of endoscopic skull base surgery $[8,9]$.

Since Hadad et al. suggested a vascularized nasoseptal flap (NSF) for skull base reconstruction [10], many authors have reported that cases of postoperative CSF leak have decreased surprisingly [11-13]. Nonetheless, postoperative placement of lumbar drainage (LD) for CSF diversion is still required, 
especially in cases with a high body mass index (BMI), opening of the third ventricle, previous history of surgery or radiation treatment, or involvement of the posterior cranial fossa [14-17]. However, LD is frequently associated with unlethal complications, such as post-puncture headache, radiculopathy, symptoms associated with over-drainage, and immobilization [18], all of which could increase the postoperative length of stay (LOS). Therefore, the development of safe and effective alternative reconstruction methods that do not require LD is necessary to reduce the incidence of LD-associated complications.

Injectable hydroxyapatite (HXA) was introduced in 1996 and is has been widely used in various fields, including orthopedic surgery, otorhinolaryngology, plastic surgery, and neurosurgery [19-21]. The HXA hardens within $5 \mathrm{~min}$ after injection under drying conditions; hence, it could be a suitable material to cover bony defects. In skull base surgery for sellar reconstruction, Chung et al. recommended injectable HXA as a substitute for NSF [7], and Kitano et al. proposed injectable HXA as a component of the multilayer technique [22]. In this study, we retrospectively evaluated the outcome of our graded reconstruction strategy after EES with injectable HXA, but without LD.

\section{Materials And Methods}

A total of 250 patients who underwent EES between June 2020 and March 2021 were retrospectively reviewed in this consecutive series. During this period, we performed EES for skull base tumors such as pituitary adenoma, craniopharyngioma, tuberculum sellae meningioma, and Rathke's cleft cyst. The degree of intraoperative CSF leak was assessed using the grading scale suggested by Esposito et al [17]. Ninety-seven patients showed an intraoperative grade II or III CSF leak and were included in the study. Patients without an intraoperative CSF leak, patients with a grade I CSF leak, and those with tumors involving the posterior fossa were excluded from this study. The study was approved by the institutional review board of our institution and was performed in compliance with relevant ethical guidelines.

Medical records of the included patients were reviewed to collect data, including demographic variables (sex, age, and BMI), diagnosis, intraoperative CSF leak grade, sellar reconstruction method used, and length of stay (LOS) in the hospital postoperatively. To investigate the integrity of NSF, postoperative MRI and rhinological status were also examined by a dedicated neuroradiologist and otorhinolaryngologist, respectively.

\section{Surgical technique}

Details of the EES have been described previously $[8,23]$. The entire surgery was performed by an endoscopic skull base surgery team comprising a neurosurgeon (D.S.K.) and an otorhinolaryngologist (S.D.H.) at a single institution. During the EES, rigid endoscopes (diameter, $4 \mathrm{~mm}$; length, $18 \mathrm{~cm}$; with $0^{\circ}$, $30^{\circ}$, or $45^{\circ}$ angle of view lenses; KARL STORZ Endoscopy Korea Co., Ltd., Seoul, Korea) were used in combination with a robotic holding arm (POINT SETTER, Mitaka Kohki Co., Ltd., Tokyo, Japan). All 
endoscopic procedures were recorded using a high-resolution camera and video recording system (KARL STORZ Endoscopy Korea Co., Ltd., Seoul, Korea).

For grade II CSF leak, we placed a fibrin sealant patch (TachoSil®, Takeda Pharmaceutical Co., Ltd., Osaka, Japan), followed by an NSF. In contrast, for cases involving grade III CSF leaks, the sellar reconstructive method included the following multi-layer technique. In this technique, (i) a collagen matrix (DuraGen ${ }^{\circledR}$, Integra LifeSciences, New Jersey, USA) was first placed into the arachnoid defect. Thereafter, (ii) an acellular dermal graft (AlloDerm ${ }^{\circledR}$, BioHorizons ${ }^{\circledR}$, Alabama, USA or MegaDerm ${ }^{\circledR}$, L\&C BIO, Gyeonggi-do, Korea), tailored according to the size of the sellar bone defect, was overlaid as an on-lay dura graft. (iii) HXA (Hydroset®, Stryker Leibinger, Freiburg, Germany) was then injected for additional closure of the sellar defect; at this step, no intraoperative CSF leak was observed from the reconstructed graft site 5-10 min after HXA injection. Finally, (iv) the NSF, already harvested at the beginning of EES, was used to cover the layered materials; thus, HXA was not exposed to the nasal cavity. Compression was applied with (v) a 12-Fr balloon catheter or two pieces of Merocel ${ }^{\circledR}$ (Medtronic, Minneapolis, USA) to stabilize the graft. Postoperatively, LD was not routinely performed.

\section{Postoperative management}

Three antibiotics (third-generation cephalosporin, quinolone, and metronidazole) were intravenously administered for 3-5 days. Intravenous or oral steroid (hydrocortisone) replacement was performed preand postoperatively. To identify the degree of tumor resection and the integrity of NSF, sellar MRI was performed one day after surgery, and otorhinolaryngological examination was performed on days 2 and 5 postoperatively. All patients were followed up at an otorhinolaryngology and endocrinology outpatient clinic at 1 week after discharge and at a neurosurgery outpatient clinic 3 weeks after discharge.

\section{Statistical analysis}

Independent variables associated with CSF leaks were analyzed using univariate analysis. The postoperative LOS was compared between the CSF leak grade II and grade III groups using an independent sample t-test. $\mathrm{P}<0.05$ was considered statistically significant. Statistical evaluations were accomplished by SPSS $\circledast$ Statistics 27 (IBM Co., New York, USA)

\section{Results}

\section{Baseline characteristics}

Among the 97 consecutive patients included in this study, 47 (48.5\%) were men and 50 (51.5\%) were women. The mean age at the time of surgery was 48.5 (range, 5-75) years, and the mean BMI was 25.7 (range, $13.9-37.1) \mathrm{kg} / \mathrm{m}^{2}$. Pituitary adenoma $(n=57)$ was the most common tumor (including four cases of Cushing's disease, three cases of acromegaly, and three cases of prolactinoma) followed by craniopharyngioma $(n=18)$, meningioma $(n=11)$, Rathke's cleft cyst $(n=4)$, germinoma $(n=4)$, chordoma $(n=1)$, cavernous malformation $(n=1)$, and pilocytic astrocytoma $(n=1)($ Table 1$)$. 
Table 1

Baseline patient characteristics

\begin{tabular}{|c|c|c|}
\hline & & Number of cases (\%) \\
\hline \multicolumn{2}{|l|}{ Total number } & $97(100)$ \\
\hline \multirow[t]{2}{*}{ Sex } & Male & $47(48.5)$ \\
\hline & Female & $50(51.5)$ \\
\hline \multirow[t]{3}{*}{ Age (years) } & $<20$ & $4(4.1)$ \\
\hline & $20-59$ & $70(72.2)$ \\
\hline & $\geq 60$ & $23(23.7)$ \\
\hline \multirow[t]{3}{*}{$\mathrm{BMI}^{\mathrm{a}}\left(\mathrm{kg} / \mathrm{m}^{2}\right)$} & $<18$ & $5(5.2)$ \\
\hline & $18-25$ & $42(43.3)$ \\
\hline & $\geq 25$ & $50(51.5)$ \\
\hline \multirow[t]{12}{*}{ Diagnosis } & Pituitary adenoma & $57(58.8)$ \\
\hline & Non-functional & $47(48.5)$ \\
\hline & Cushing's disease & $4(4.1)$ \\
\hline & Acromegaly & $3(3.1)$ \\
\hline & Prolactinoma & $3(3.1)$ \\
\hline & Craniopharyngioma & $18(18.6)$ \\
\hline & Meningioma & $11(11.3)$ \\
\hline & Rathke's cleft cyst & $4(4.1)$ \\
\hline & Germinoma & $4(4.1)$ \\
\hline & Chordoma & $1(1.0)$ \\
\hline & Cavernous malformation & $1(1.0)$ \\
\hline & Pilocytic astrocytoma & $1(1.0)$ \\
\hline
\end{tabular}

Clinical and reconstruction outcome

During the follow-up period (mean, 8.7 months), overall gross- and near-total resection was achieved in $50(51.5 \%)$ and 39 patients (40.2\%), respectively (Table 2$)$. Among the 97 patients, grade II and grade III CSF leaks were noted in 48 (49.5\%) and 49 (50.5\%) patients, respectively (Table 3). We applied the modified reconstructive methods according to the CSF leak grade. We placed a fibrin sealant patch 
(TachoSil®, Takeda Pharmaceutical Co., Ltd., Osaka, Japan), followed by an NSF in patients with grade II CSF leak; for patients with grade III CSF leak, we applied a multi-layer technique using a collagen matrix, an acellular dermal graft, HXA, and an NSF. During the follow-up period, no postoperative CSF leak was observed in any of the patients. On univariate analysis, we found that no significant variable affected the outcome of the reconstruction.

Table 2

Extent of tumor removal and pathological diagnosis of patients

\begin{tabular}{|lllll|}
\hline Diagnosis & \multicolumn{2}{c}{ Extent $^{2}$ of removal } & \multirow{2}{*}{ Number of cases } \\
\cline { 2 - 4 } & GTR & NTR & STR & \\
\hline Pituitary adenoma & 34 & 21 & 2 & 57 \\
\hline Non-functional & 28 & 18 & 1 & 47 \\
\hline Cushing's disease & 2 & 1 & 1 & 4 \\
\hline Acromegaly & 2 & 1 & 0 & 3 \\
\hline Prolactinoma & 2 & 1 & 0 & 3 \\
\hline Craniopharyngioma & 8 & 9 & 1 & 18 \\
\hline Meningioma & 6 & 3 & 2 & 11 \\
\hline Rathke's cleft cyst & 1 & 3 & 0 & 4 \\
\hline Germinoma & 0 & 1 & 3 & 4 \\
\hline Chordoma & 1 & 0 & 0 & 1 \\
\hline Cavernous malformation & 0 & 1 & 0 & 1 \\
\hline Pilocytic astrocytoma & 0 & 1 & 0 & 1 \\
\hline Total & 50 & 39 & 8 & 97 \\
\hline aGTR, gross total resection; NTR, near-total resection; STR, subtotal resection \\
\hline
\end{tabular}


Table 3

CSF leak grade and pathological diagnosis of patients

\begin{tabular}{|c|c|c|c|}
\hline \multirow[t]{2}{*}{ Variable } & \multicolumn{2}{|c|}{ Number of cases } & \multirow[t]{2}{*}{ p-value } \\
\hline & Grade II & Grade III & \\
\hline Female sex & 27 & 23 & 0.419 \\
\hline Age $<50$ years & 20 & 25 & 0.418 \\
\hline $\mathrm{BMI}^{\mathrm{b}} \geq 25\left(\mathrm{~kg} / \mathrm{m}^{2}\right)$ & 23 & 27 & 0.545 \\
\hline Pituitary adenoma & 41 & 16 & $0.000^{*}$ \\
\hline Non-functional & 33 & 14 & $0.000^{*}$ \\
\hline Cushing's disease & 4 & 0 & 0.056 \\
\hline Acromegaly & 2 & 1 & 0.617 \\
\hline Prolactinoma & 2 & 1 & 0.617 \\
\hline Craniopharyngioma & 0 & 18 & $0.000^{*}$ \\
\hline Meningioma & 4 & 7 & 0.524 \\
\hline Rathke's cleft cyst & 2 & 2 & 1.000 \\
\hline Germinoma & 1 & 3 & 0.617 \\
\hline Chordoma & 0 & 1 & 1.000 \\
\hline Cavernous malformation & 0 & 1 & 1.000 \\
\hline Pilocytic astrocytoma & 0 & 1 & 1.000 \\
\hline Total & 48 & 49 & \\
\hline
\end{tabular}

We compared the postoperative LOS between the grade II and grade III CSF leak groups. The mean LOS was 6.68 (range, 3-14) days in the grade II CSF leak group and 7.38 (range, 4-15) days in the grade III CSF leak group. There was no significant difference in the LOS between the two groups $(p=0.212)$ (Table 4). 
Table 4

Postoperative length of stay (LOS) and CSF leak grade

\begin{tabular}{|c|c|c|}
\hline${ }^{a}$ CSF leak grade & LOS (days) & p-value ${ }^{b}$ \\
\hline Grade II & $6.68^{\star}$ & 0.212 \\
\hline Grade III & $7.38^{\star \star}$ & \\
\hline \multicolumn{3}{|c|}{${ }^{a}$ CSF, cerebrospinal fluid } \\
\hline \multicolumn{3}{|c|}{${ }^{\mathrm{b}}$ Independent sample t-test } \\
\hline \multicolumn{3}{|c|}{$\begin{array}{l}\text { *One patient was excluded due to postoperative subarachnoid hemorrhage and required a longer } \\
\text { admission period for consequent management. }\end{array}$} \\
\hline
\end{tabular}

\section{Status of integrity of the NSF}

To evaluate the integrity of the NSF, postoperative MRI was performed within a day after surgery. A Cshaped configuration of the flap adjacent to the skull base covering the sellar defect in both coronal and sagittal views was reviewed by an authoritative neuroradiologist (S.T.K.). Additionally, rhinological examination was performed by a dedicated otorhinolaryngologist. MRI results showed that NSF was not enhanced in 12 of the 97 patients examined (12.4\%, 7 with grade II and 5 with grade III CSF leaks), which was confirmed by rhinological examination.

\section{Adverse effects associated with HXAgraft}

During the overall follow-up period, we did not observe crust, seroma, or infection around the NSF or HXA in routine rhinological examinations. In addition, there was no allergic reaction or aseptic meningitis in the group that received the HXA graft.

\section{Discussion}

Recently, EES for skull base tumors has become a major surgical technique in modern skull base surgery. Despite its surgical and technical limitations compared with the transcranial approach, it provides a favorable surgical outcome [24-26]. However, postoperative CSF leak, a recognized complication associated with EES $[27,28]$, remains a matter of concern, and reconstruction of the barriers between the arachnoid space and sinonasal tract continues to be a challenge [10]. For grade III CSF leaks, which is an inevitable result after the suprasellar or transclival approach, lumbar CSF diversion can contribute to improved reconstruction outcomes $[17,18]$. However, LD often poses risks of associated complications such as post-puncture headache, radiculopathy, symptoms associated with over-drainage, and longstanding immobilization. 
The recommended maintenance period of $\operatorname{LD}$ varies among studies $[17,18]$, with no consensus. In clinical practice, postoperative LD should be maintained for a minimum of 3-5 days, resulting in prolonged LOS in hospitals. Therefore, an alternative technique without LD is required to manage grade III CSF leaks. Herein, we analyzed the efficacy of HXA and its potential to replace LD in high-flow intraoperative CSF leaks by comparing the LOS between patients with grade II and grade III CSF leaks. We found no significant difference in the LOS between the two groups, and no serious complications associated with injectable HXA were identified.

In contrast to a previous study on the complications of HXA [29], our study showed acceptable clinical results with HXA. For successful grafting of HXA, optimal condition of the perigraft environment is crucial because HXA weakens in humid environments and can fracture easily. Some materials, such as HXA, reabsorb too slowly, which can cause inflammation. Therefore, it is critical to maintain minimal or zero infection rate after HXA grafting. We suggest that the acellular dermis for dural grafting might function as a barrier between the arachnoid space and the injected HXA, and it may prevent stray HXA particles from entering the intradural space. In addition, in the study, placement of a vascularized NSF completely covered the grafted HXA and prevented it from exposure to the outer side of the sinonasal tract. Thus, the combination of acellular dermal graft with HXA could have contributed to our favorable results; no patient showed HXA-related complications, such as aseptic meningitis or foreign body reaction.

Our study had several limitations. Since this study was designed as a retrospective consecutive series, we did not compare the LOS between patients treated with injectable HXA and those who required LD. Furthermore, data were collected from a single institution by a single surgery team, and thus, might not represent the patient-group in general. Although the size of the tumor and the extent of the sellar defect varied among individual patients, these were not considered in our study.

\section{Conclusions}

The graded surgical repair strategy using injectable HXA in combination with acellular dermal grafts provided effectiveness and safety in sellar reconstruction after EES without postoperative CSF leak. Combined use of injectable HXA and acellular dermal grafts for high-flow CSF leak can limit LD requirement, without significant risks. By decreasing the need for LD, HXA may allow early ambulation and shorten the LOS after surgery.

\section{Abbreviations}

$\mathrm{BMI}$, body mass index; CSF, cerebrospinal fluid; CT, computed tomography; EES, endoscopic endonasal surgery; GTR, gross total resection; HXA, hydroxyapatite; LD, lumbar drainage; LOS, length of stay; MRI, magnetic resonance imaging; NSF, nasoseptal flap; NTR, near-total resection; STR, subtotal resection

\section{Declarations}


Funding: This research received no external funding.

Conflicts of interest/Competing interests: The authors declare no conflict of interest.

Ethics approval: This retrospective study was reviewed and approved by the Institutional Review Board of Samsung Medical Center in Seoul, Korea. The study was performed in accordance with the World Medical Association Declaration of Helsinki.

Availability of data and material: The data are available upon reasonable request to the corresponding author.

Code availability: Not applicable

Consent to participate: Patient consent was waived due to the retrospective study design.

Consent for publication: Patient consent was waived due to the retrospective study design

Contributions: Conceptualization: Chang-Min Ha, Doo-Sik Kong; Methodology: Chang-Min Ha, Doo-Sik Kong; Data curation: Sang Duk Hong, Doo-Sik Kong; Resources; Chang-Min Ha, Sang Duk Hong, Doo-Sik Kong; Validation: Chang-Min Ha, Sang Duk Kong, Doo-Sik Kong; Formal Analysis: Chang-Min Ha; Investigation: Doo-Sik Kong; Project administration: Doo-Sik Kong; Supervision: Jung Won Choi, Ho Jun Seol, Do-Hyun Nam, Jung-II Lee; Visualization: Chang-Min Ha, Doo-Sik Kong; Writing - original draft: Chang-Min Ha; Writing - review \& editing: Doo-Sik Kong

All authors have read and agreed to the published version of the manuscript.

\section{References}

1. Arbolay OL, González JG, González RH, Gálvez YH (2009) Extended endoscopic endonasal approach to the skull base. Minim Invasive Neurosurg 52:114-118. https://doi.org/10.1055/s-0028-1119414

2. Ceylan S, Koc K, Anik I (2009) Extended endoscopic approaches for midline skull-base lesions. Neurosurg Rev 32:309-319; discussion 318-309. https://doi.org/10.1007/s10143-009-0201-9

3. d'Avella E, Angileri F, de Notaris M, Enseñat J, Stagno V, Cavallo LM, Gonzales JB, Weiss A, PratsGalino A (2014) Extended endoscopic endonasal transclival approach to the ventrolateral brainstem and related cisternal spaces: anatomical study. Neurosurg Rev 37:253-260; discussion 260. https://doi.org/10.1007/s10143-014-0526-x

4. Kassam A, Carrau RL, Snyderman CH, Gardner P, Mintz A (2005) Evolution of reconstructive techniques following endoscopic expanded endonasal approaches. Neurosurg Focus 19:E8.

5. Cappabianca P, Cavallo LM, Colao A, Del Basso De Caro M, Esposito F, Cirillo S, Lombardi G, de Divitiis E (2002) Endoscopic endonasal transsphenoidal approach: outcome analysis of 100 consecutive procedures. Minim Invasive Neurosurg 45:193-200. https://doi.org/10.1055/s-200236197 
6. Cappabianca P, Cavallo LM, Colao A, de Divitiis E (2002) Surgical complications associated with the endoscopic endonasal transsphenoidal approach for pituitary adenomas. J Neurosurg 97:293-298. https://doi.org/10.3171/jns.2002.97.2.0293

7. Chung SB, Nam DH, Park K, Kim JH, Kong DS (2012) Injectable hydroxyapatite cement patch as an on-lay graft for the sellar reconstructions following endoscopic endonasal approach. Acta Neurochir (Wien) 154:659-664; discussion 664. https://doi.org/10.1007/s00701-012-1293-5

8. Khatiwala RV, Shastri KS, Peris-Celda M, Kenning T, Pinheiro-Neto CD (2020) Endoscopic Endonasal Reconstruction of High-Flow Cerebrospinal Fluid Leak with Fascia Lata "Button" Graft and Nasoseptal Flap: Surgical Technique and Case Series. J Neurol Surg B Skull Base 81:645-650. https://doi.org/10.1055/s-0039-1693124

9. Hasegawa H, Shin M, Kondo K, Saito N (2018) Reconstruction of Dural Defects in Endoscopic Transnasal Approaches for Intradural Lesions Using Multilayered Fascia with a Pressure-Control Spinal Drainage System. World Neurosurg 114:e1316-e1324. https://doi.org/10.1016/j.wneu.2018.03.209

10. Hadad G, Bassagasteguy L, Carrau RL, Mataza JC, Kassam A, Snyderman CH, Mintz A (2006) A novel reconstructive technique after endoscopic expanded endonasal approaches: vascular pedicle nasoseptal flap. Laryngoscope 116:1882-1886. https://doi.org/10.1097/01.mlg.0000234933.37779.e4

11. Cavallo L, Prevedello D, Esposito F, Laws E, Dusick J, Messina A (2008) The role of the endoscope in the transsphenoidal management of cystic lesions of the sellar region. Neurosurg Rev 31:55-64.

12. Patel KS, Komotar RJ, Szentirmai O, Moussazadeh N, Raper DM, Starke RM, Anand VK, Schwartz TH (2013) Case-specific protocol to reduce cerebrospinal fluid leakage after endonasal endoscopic surgery. J Neurosurg 119:661-668. https://doi.org/10.3171/2013.4.Jns13124

13. Soudry E, Psaltis AJ, Lee KH, Vaezafshar R, Nayak JV, Hwang PH (2015) Complications associated with the pedicled nasoseptal flap for skull base reconstruction. Laryngoscope 125:80-85. https://doi.org/10.1002/lary.24863

14. Mehta GU, Oldfield EH (2012) Prevention of intraoperative cerebrospinal fluid leaks by lumbar cerebrospinal fluid drainage during surgery for pituitary macroadenomas. J Neurosurg 116:12991303. https://doi.org/10.3171/2012.3.Jns112160

15. Dehdashti AR, Stofko D, Okun J, Obourn C, Kennedy T (2016) Endoscopic Endonasal Reconstruction of Skull Base: Repair Protocol. J Neurol Surg B Skull Base 77:271-278. https://doi.org/10.1055/s0035-1568871

16. Liu B, Wang Y, Zheng T, Liu S, Lv W, Lu D, Chen L, Chen L, Ma T, Gao G, Qu Y, He S (2020) Effect of Intraoperative Lumbar Drainage on Gross Total Resection and Cerebrospinal Fluid Leak Rates in Endoscopic Transsphenoidal Surgery of Pituitary Macroadenomas. World Neurosurg 135:e629-e639. https://doi.org/10.1016/j.wneu.2019.12.100

17. Esposito F, Dusick JR, Fatemi N, Kelly DF (2007) Graded repair of cranial base defects and cerebrospinal fluid leaks in transsphenoidal surgery. Oper Neurosurg (Hagerstown) 60:295-303; 
discussion 303-294. https://doi.org/10.1227/01.Neu.0000255354.64077.66

18. Zwagerman NT, Wang EW, Shin SS, Chang YF, Fernandez-Miranda JC, Snyderman CH, Gardner PA (2018) Does lumbar drainage reduce postoperative cerebrospinal fluid leak after endoscopic endonasal skull base surgery? A prospective, randomized controlled trial. J Neurosurg:1-7. https://doi.org/10.3171/2018.4.Jns172447

19. Baker SB, Weinzweig J, Kirschner RE, Bartlett SP (2002) Applications of a new carbonated calcium phosphate bone cement: early experience in pediatric and adult craniofacial reconstruction. Plast Reconstr Surg 109:1789-1796. https://doi.org/10.1097/00006534-200205000-00003

20. Costantino PD, Chaplin JM, Wolpoe ME, Catalano PJ, Sen C, Bederson JB, Govindaraj S (2000) Applications of fast-setting hydroxyapatite cement: cranioplasty. Otolaryngol Head Neck Surg 123:409-412. https://doi.org/10.1067/mhn.2000.107679

21. Durham SR, McComb JG, Levy ML (2003) Correction of large ( $>25 \mathrm{~cm}(2))$ cranial defects with "reinforced" hydroxyapatite cement: technique and complications. Neurosurgery 52:842-845; discussion 845. https://doi.org/10.1227/01.neu.0000054220.01290.8e

22. Kitano M, Taneda M (2007) Icing and multilayering technique of injectable hydroxyapatite cement paste for cranial base reconstruction after transsphenoidal surgery: technical note. Neurosurgery 61:E53-54; discussion E54. https://doi.org/10.1227/01.neu.0000289713.80178.ce

23. Kuga D, Toda M, Ozawa H, Ogawa K, Yoshida K (2019) Endoscopic Endonasal Approach Combined with a Simultaneous Transcranial Approach for Giant Pituitary Tumors. World Neurosurg 121:173179. https://doi.org/10.1016/j.wneu.2018.10.047

24. Moussazadeh N, Prabhu V, Bander ED, Cusic RC, Tsiouris AJ, Anand VK, Schwartz TH (2016) Endoscopic endonasal versus open transcranial resection of craniopharyngiomas: a case-matched single-institution analysis. Neurosurg Focus 41:E7. https://doi.org/10.3171/2016.9.Focus16299

25. Farquhar D, Kim L, Worrall D, Chiu A, Lee JY, Khalili S, Grady S, O'Malley BW, Jr., Kennedy DW, Newman JG, Palmer JN, Adappa ND (2016) Propensity score analysis of endoscopic and open approaches to malignant paranasal and anterior skull base tumor outcomes. Laryngoscope 126:1724-1729. https://doi.org/10.1002/lary.25885

26. Abergel A, Cavel O, Margalit N, Fliss DM, Gil Z (2012) Comparison of quality of life after transnasal endoscopic vs open skull base tumor resection. Arch Otolaryngol Head Neck Surg 138:142-147. https://doi.org/10.1001/archoto.2011.1146

27. Shiley SG, Limonadi F, Delashaw JB, Barnwell SL, Andersen PE, Hwang PH, Wax MK (2003) Incidence, etiology, and management of cerebrospinal fluid leaks following trans-sphenoidal surgery. Laryngoscope 113:1283-1288. https://doi.org/10.1097/00005537-200308000-00003

28. Hannan CJ, Almhanedi H, Al-Mahfoudh R, Bhojak M, Looby S, Javadpour M (2020) Predicting postoperative cerebrospinal fluid (CSF) leak following endoscopic transnasal pituitary and anterior skull base surgery: a multivariate analysis. Acta Neurochir (Wien) 162:1309-1315. https://doi.org/10.1007/s00701-020-04334-5 
29. Ahn JC, Cho SW, Kim DK, Han DH, Kim DY, Rhee CS, Lee CH, Kim YH, Paek SH, Won TB (2019) Recovery period of sinonasal quality of life and its associated factors after endoscopic endonasal approach for anterior skull base tumors. Acta Otolaryngol 139:461-466. https://doi.org/10.1080/00016489.2019.1574982 